\title{
Inter- and Intraspecific Variability in Infectivity and Effectiveness of Five Glomus sp. Strains and Growth Response of Tomato Host
}

\author{
${ }^{1}$ T. TAKÁCS, ${ }^{1}$ I. BIRÓ, ${ }^{1}$ A. ANTON and ${ }^{2}$ HE CHAOXING \\ ${ }^{1}$ Research Institute for Soil Science and Agricultural Chemistry (RISSAC) of the \\ Hungarian Academy of Sciences, Budapest and ${ }^{2}$ Institute of Vegetables and Flowers \\ (IVF) of the Chinese Academy of Agricultural Sciences (CAAS), Beijing (China)
}

\section{Introduction}

In the last decades the high input of chemicals, fertilizers and pesticides have caused pollution, degradation and decreased biodiversity in agro-ecosystems. Conventional agriculture has been replaced by low input sustainable cropping systems in which rhizosphere microorganisms play an important role in improving the nutrition, vitality and fitness of plants. One of the most important groups of soil microorganisms is mycorrhizal fungi. Arbuscular mycorrhizal (AM) fungi are obligatory biotrophic symbionts living in the roots of most terrestrial plants. The great majority of the economically important crops, vegetables, fruits and ornamentals form AM symbiosis. AM fungi establish a direct connection between the soil and the plant by colonizing the host root and soil. AM fungi generally occur in most of the terrestrial ecosystems, with the exception of habitats with extreme soil characteristics $(\mathrm{pH}$, soil pollution etc.). Numerous publications have reported that mycorrhizal plants with high surface hyphal network are more efficient in nutrient acquisition, transport and uptake than non-colonized plants, therefore AM fungi (AMF) have an especially beneficial effect on plant growth and plant nutrition under stressed conditions (LANDWEHR et al., 2002; SIMON \& BIRÓ, 2005; TAKÁCS et al., 2005). AMF can improve the protection against some soil-borne pathogens (CLARK \& ZETO, 2000; MARSCHNER, 1997). The growth stimulating effect of AMF inoculation is influenced by several factors, including the individual properties of plant and fungi symbiotic partners, too. Plants in natural ecosystems depend on mycorrhizal associations in varying degrees, which is genetically determined (JANOS, 1988; TAWARAYA, 2003). The dependency on mycorrhiza fungi can be calculated from the growing parameters of mycorrhized and non-mycorrhized plants cultivated under the same conditions. Optimal growth of strongly mycotroph plants can be assured only with the fungal partner, even in good nutritional conditions (SIEVERDING, 1991). The mycorrhizal dependency (MD) of less mycotroph plants 
is greatly influenced by root morphology and the ecological features of the habitat. The fungal dependency of plants decreases with higher root density and favourable circumstances. The mycorrhizal dependency of leguminous plants is higher than that of grasses in general, with the exception of Lupinus genus. Tomato (Lycopersicon esculentum L.) is recognized as a mycotrophic plant (KUBOTA et al., 2005; SCHROEDER \& JANOS, 2004). The usefulness of AMF inoculation for improving the fitness and vitality of tomato host has been described by several authors in stress conditions, too (KARAGIANNIDIS et al., 2002; REGVAR et al., 2003). Similarly to plant partners, significant differences can be found among AM fungi species in infection parameters and in plant response to AMF colonization. The functional diversity of AMF community may regulate the diversity of plant species and plays an important role in natural ecosystem stability (SzILI-KovÁCS, 2004). The nearly 150 described AMF species colonize most of the terrestrial plants (http://invam.caf.wvu.edu/fungi/taxonomy/nomenclature.htm). This suggests that the relatively few members of the Glomeromycota species probably have a great functional heterogeneity (MUNKVOLD et al., 2004).

The aim of the present work was to investigate the intra- and interspecific variability in infectivity and effectiveness of five Glomus sp. strains and the response of tomato (Lycopersicon esculentum L.) host to AMF inoculation in a pot experiment.

\section{Materials and Methods}

The soil samples originated from selected plots of the experimental site of RISSAC in Nagyhörcsök (Hungary). The soil is classified as a calcareous loamy chernozem with the following main characteristics: $\mathrm{pH}\left(\mathrm{H}_{2} \mathrm{O}\right)$ : 7.5; $\mathrm{pH}(\mathrm{KCl})$ : 7.2; $\mathrm{CaCO}_{3}$ content: 5-6.3\%; humus content: $3.2 \%$; clay fraction: $(<0.002 \mathrm{~mm}) 20 \%$; silt (0.02-0.05 mm): 40\%, AL- $\mathrm{P}_{2} \mathrm{O}_{5}: 90-120 \mathrm{mg} \cdot \mathrm{kg}^{-1}, \mathrm{AL}-\mathrm{K}_{2} \mathrm{O}: 160-190 \mathrm{mg} \cdot \mathrm{kg}^{-1}$, total $\mathrm{N}$ : $1800-2100 \mathrm{mg} \cdot \mathrm{kg}^{-1}, \mathrm{C} / \mathrm{N}$ ratio: $7.7-8.5$. The original nutrient supply of the soil is medium to weak.

The pot trial was set up in five replications with sterilized soil in a growth chamber under controlled climatic conditions (temperature between 25 and $17{ }^{\circ} \mathrm{C}$, with a 18 (25000 lux $) / 6 \mathrm{~h} \mathrm{light/dark} \mathrm{period).} \mathrm{The} \mathrm{soil} \mathrm{samples} \mathrm{were} \mathrm{sterilized} \mathrm{twice}$ with $1.5 \mathrm{~h}$ steaming on $120 \mathrm{kPa}$ separated by a $24 \mathrm{~h}$ cooling period. The tomato (Lycopersicon esculentum L.) plants were inoculated with Glomus claroideum (BEG23) (SCHENCK \& SMITH, 1982), Glomus geosporum (BEG11) (WALKER, 1982), Glomus fasciculatum (BEG53) (GERDEMANN, 1965), Glomus mosseae (BEG12) (NICOLSON \& GERDEMANN, 1968) strains and a Glomus mosseae $(\mathrm{H})$ AMF culture produced by authors $\left(5 \mathrm{w} / \mathrm{w} \%\right.$ AMF inoculum pot $\left.^{-1}\right)$. Glomus mosseae $(\mathrm{H})$ is a single spore strain originating from a sandy soil in Örbottyán (Hungary). A growth medium was composed of two parts of sand and one part of calcareous chernozem soil (Nagyhörcsök). It was pasteurized with the former method and applied for AMF inoculum production. For the inocula production the pot cultures of infected white clover hosts (Trifolium repens L.) were grown for three months in a growth chamber under controlled climatic conditions (tempera- 
ture between 25 and $17{ }^{\circ} \mathrm{C}, 18 / 6 \mathrm{~h}$ light/dark period). After controlling AMF infectivity, the infected roots and the spores of the species were homogenized with the growth medium. Generally high infection $(\mathrm{F} \%=93.3-100 \%)$ was determined in clover root for each Glomus sp. culture.

The dry biomass production, the micro- and macronutrient concentrations of the shoots and the parameters of mycorrhizal infection were determined after a 40-day growth period. The root samples were cleared and stained with acid glycerol aniline blue (PHILlips \& HAYMAN, 1970). The frequency (F\%) and the intensity (M) of mycorrhizal infection and the quantity of the arbuscules $(\mathrm{a} \%, \mathrm{~A} \%)$ were estimated by the five class system (TROUVELOT et al., 1986). The plant macro- and microelement concentrations were assessed after wet digestion of the air-dried plant samples with cc. $\mathrm{HNO}_{3}+\mathrm{cc} . \mathrm{H}_{2} \mathrm{O}_{2}$. Shoot macro- and microelement contents were measured by inductively coupled plasma atomic emission spectrometry (ICP-AES).

The statistical analysis of experimental data was carried out by one way ANOVA for detecting significant differences between treatment means. The significance level threshold was set at $\mathrm{P}<0.05$.

\section{Results and Discussion}

Intraspecific and interspecific differences were found in the infectivity and effectiveness of mycorrhizae. Each AM fungi species or strain caused different and distinct changes in the growth and nutrient uptake of the host plant. The AMF root colonization parameters together $(\mathrm{F} \%, \mathrm{M}, \mathrm{a} \%, \mathrm{~A} \%)$ (Table 1) characterize the infectivity of various Glomus species. The effectiveness of AMF inoculation with the different fungi strains was concluded from the plant response to the presence of AMF in the root system of tomato. Plant growth and nutrition were evaluated by biomass production, mycorrhizal dependency (MD) and shoot micro- and macroelement concentrations (Table 2).

Table 1

Root colonization parameters in tomato roots inoculated with various Glomus sp. strains

\begin{tabular}{|l|c|c|c|c|}
\hline \multirow{2}{*}{ AMF strains } & \multicolumn{4}{c|}{ AMF colonization parameters } \\
\cline { 2 - 5 } & $\mathrm{F} \%$ & $\mathrm{M}$ & $\mathrm{a} \%$ & $\mathrm{~A} \%$ \\
\hline Gl. mosseae (BEG12) & 43.78 & 9.26 & 21.96 & 2.46 \\
Gl. mosseae (H) & 30.44 & 7.92 & 26.97 & 2.24 \\
Gl. geosporum (BEG11) & 19.78 & 4.18 & 1.64 & 0.06 \\
Gl. claroideum (BEG23) & 14.17 & 2.05 & 3.17 & 0.11 \\
Gl. fasciculatum (BEG53) & 27.33 & 6.00 & 19.09 & 1.06 \\
Mean & 27.1 & 5.88 & 14.56 & 1.19 \\
LSD $_{5 \%}$ & 13.69 & 5.07 & 24.61 & 2.03 \\
\hline
\end{tabular}

Remarks: F\%: infection frequency of AMF; M: intensity of AMF infection; a\%: extent of arbuscules in root samples with colonized AMF; A\%: arbuscular richness in the root system with colonized AMF. Data are means of 5 replications. $\mathrm{LSD}_{5 \%}$ : least significant difference at $\mathrm{P}<0.05$ 
Table 2

Effectiveness parameters of AMF in mycorrhizal tomato inoculated with different Glomus sp. strains compared to non-mycorrhizal plants

\begin{tabular}{|c|c|c|c|c|c|c|c|}
\hline & \multicolumn{6}{|c|}{ Mycorrhizal treatments } & \multirow{4}{*}{$\mathrm{LSD}_{5 \%}$} \\
\hline & \multirow{3}{*}{$\begin{array}{l}\text { Non- } \\
\text { inocu- } \\
\text { lated }\end{array}$} & \multicolumn{5}{|c|}{ AMF inoculated } & \\
\hline & & $\begin{array}{c}\text { Gl. } \\
\text { mosseae }\end{array}$ & $\begin{array}{c}\text { Gl. } \\
\text { mosseae }\end{array}$ & $\begin{array}{l}\text { Gl. geo- } \\
\text { sporum }\end{array}$ & $\begin{array}{c}\text { Gl. } \\
\text { claroideum }\end{array}$ & $\begin{array}{l}\text { Gl. fas- } \\
\text { ciculatum }\end{array}$ & \\
\hline & & (BEG12) & $(\mathrm{H})$ & (BEG11) & (BEG23) & (BEG53) & \\
\hline \multicolumn{8}{|c|}{ Shoot dry matter, $g \cdot$ pot $^{-1}$} \\
\hline & 1.18 & 1.87 & 2.62 & 2.18 & 2.16 & 2.03 & 0.77 \\
\hline \multicolumn{8}{|c|}{ Mycorrhizal dependency (MD), \% } \\
\hline & - & 36.9 & 55.0 & 45.9 & 45.4 & 41.9 & 9.8 \\
\hline \multicolumn{8}{|c|}{ Growth response, \% } \\
\hline & - & 58.5 & 122 & 84.7 & 83.0 & 72.0 & 32.4 \\
\hline \multicolumn{8}{|c|}{ Macro- and microelement concentrations in shoots, $\mathrm{mg} \cdot \mathrm{kg}^{-1}$} \\
\hline $\mathrm{N}$ & 24975 & 27750 & 26500 & 21160 & 25275 & 28250 & 2300 \\
\hline $\mathrm{P}$ & 2517 & 3282 & 3264 & 3042 & 3115 & 3149 & 415 \\
\hline K & 42992 & 48642 & 49406 & 45320 & 45162 & 51547 & 2950 \\
\hline $\mathrm{S}$ & 3651 & 3589 & 3567 & 4397 & 3851 & 3518 & 357 \\
\hline $\mathrm{Ca}$ & 29523 & 27138 & 27964 & 29825 & 28221 & 30609 & n.s. \\
\hline $\mathrm{Mg}$ & 3151 & 2799 & 2733 & 3148 & 2708 & 3410 & 323 \\
\hline $\mathrm{Co}$ & 0.190 & 0.133 & 0.140 & 0.294 & 0.187 & 0.240 & n.s. \\
\hline $\mathrm{Cu}$ & 9.15 & 10.04 & 8.47 & 9.31 & 8.85 & 9.07 & 1.11 \\
\hline $\mathrm{Mn}$ & 74.13 & 60.06 & 55.38 & 79.68 & 66.16 & 76.52 & 12.43 \\
\hline Mo & 1.165 & 1.371 & 1.311 & 2.220 & 1.672 & 1.493 & 0.393 \\
\hline $\mathrm{Zn}$ & 10.34 & 11.00 & 8.36 & 13.50 & 11.80 & 11.08 & 1.67 \\
\hline $\mathrm{Ni}$ & 1.25 & 0.646 & 0.656 & 1.375 & 1.281 & 1.003 & 0.347 \\
\hline
\end{tabular}

Remarks: Growth response (\%): [(Parameter with mycorrhiza-Parameter without mycorrhiza)/Parameter without mycorrhiza] $\times 100$; MD (\%): [(Parameter with mycorrhizaParameter without mycorrhiza)/Parameter with mycorrhiza $] \times 100$. Data are the mean of 5 replications. $\mathrm{LSD}_{5 \%}$ : least significant difference at $\mathrm{P}<0.05$; n.s.: no significant differences between data

Microscopic observations of stained tomato roots showed no presence of AMF structures in non-inoculated plants. The highest root colonization, frequency and intensity of infection $(\mathrm{F} \%, \mathrm{M})$ or arbuscular richness $(\mathrm{a} \%, \mathrm{~A} \%)$ occurred in the root of tomato inoculated with the two Gl. mosseae strains (Table 1). No significant differences were found between the infectivity of Gl. mosseae strains. The least infective fungal partner of colonized tomato was the Gl. claroideum (BEG23). The rate of AMF colonization (arbuscular richness) showed a close correlation to growth responses and nutrient uptake of the host.

The biomass production of tomato increased significantly in the presence of AM symbiosis, with the exception of Gl. mosseae (BEG12) infected tomato (Table 2). 
The degree of host growth responses to AMF colonization is expressed as mycorrhizal dependency (MD) (PLENCHETTE et al., 1983). The mean values of MD were calculated from shoot dry matter weight and varied between $36 \%$ and $55 \%$. Calculated from the same data, the greatest differences in growth response (\%) and in mycorrhizal dependence (MD) to AMF colonization were detected between the two Gl. mosseae cultures of different origin (Table 2).

TAWARAYA (2003) studied 250 plant species belonging to field crops, forage crops, wild grasses, forbs and trees and discussed the factor affecting the differences in mean values of MD. In his review (TAWARAYA, 2003), the mycorrhizal dependency of tomato was found to be $59 \%$ at medium infection level (50\%). Tomato plants were colonized by indigenous AM fungi. MD of the same plant species differed in accordance with the colonization of various mycorrhizal fungi. The MD differences agreed with differences of external hyphae network development and $\mathrm{P}$ transport activity.

The effectiveness of the fungal partner can also be indicated by the impact of AMF colonization on nutrients. Mycorrhizal inoculation improved the phosphate (P) and the potassium (K) uptake of tomato (Table 2), which is in agreement with the observations of AL-KARAKI (2000) and KARAGIANNIDIS et al. (2002). Similarly to the host's $\mathrm{P}$ and $\mathrm{K}$ uptake, AMF colonization increased the nitrogen $(\mathrm{N})$ content of shoots, with the exception of Gl. geosporum (BEG11) inoculation. The highest P and $\mathrm{K}$ element contents appeared in the shoots of tomato treated with the Gl. mosseae strains.

The most commonly reported beneficial effect of AMF on plant nutrition is the enhancement of phosphate $(\mathrm{P})$ uptake, but the uptake of other nutrients - such as nitrogen $(\mathrm{N})$, both in ammonium $\left(\mathrm{NH}_{4}{ }^{+}\right)$and nitrate $\left(\mathrm{NO}_{3}{ }^{-}\right)$forms, zinc $(\mathrm{Zn})$, copper $(\mathrm{Cu}$ ), and potassium $(\mathrm{K})$ may also be assisted by AMF (CLARK \& ZETO, 2000; HARRIER \& WATSON, 2003; PARÁDI et al., 2003; TAKÁCS \& VÖRÖS, 2003). According to MARSCHNER \& DELL (1994) $80 \%, 25 \%, 10 \%, 25 \%$ and $60 \%$ of the P, N, $\mathrm{K}, \mathrm{Zn}$ and $\mathrm{Cu}$, respectively, can be transported through the AMF hyphae to the plant. In the presence of arbuscular mycorrhizae the increased $\mathrm{P}$ transport from the soil to the host has been attributed to the highly absorptive hyphae surface and the increased availability of less soluble $\mathrm{P}$ sources. In addition to the direct effect on $\mathrm{P}$ uptake of the host plant, AMF also have an indirect effect on the rhizosphere microbial community. The density of phosphorus mobilizing microorganisms is greater in the mycorrhizosphere as compared to the rhizosphere of non-mycorrhizal plants (AZCÓN-AGUILAR \& BAREA, 1992). As a net result, the P influx in roots of mycorrhizal plants can be three or five times higher than in a non-colonized plant (HARRIER \& WATSON, 2003; MARSCHNER, 1997).

The role of AMF in the uptake of magnesium $(\mathrm{Mg})$, calcium $(\mathrm{Ca})$ and sulphur (S) is less known. Acquisition of $\mathrm{Mg}$ and $\mathrm{Ca}$ by $\mathrm{AMF}$ is variable and depends on soil nutrition status, $\mathrm{pH}$, plant and fungi species. COOPER \& TINKER (1978) proved sulphur $\left({ }^{35} \mathrm{~S}\right)$ accumulation by fungal hyphae element transport in white clover infected with Gl. mosseae. RAJU et al. (1990) investigated the impact of AMF colonization on the sulphur content of soybean inoculated with Gl. macrocarpum, Gl. fasciculatum and Gl. intraradices species. Each AM fungi species increased the S 
uptake of the host plant. Colonization by Gl. macrocarpum was the most efficient. According to AZCON and BAREA (1992) mycorrhizal plants contain less calcium than non-mycorrhizal ones. The difference in $\mathrm{Ca}$ content may be caused by the morphological changes in the infected root. In the present study no significant differences were found among the effects of Glomus sp. strains on the sulphur (S) concentration of tomato shoots. The shoots' sulphur (S) content was significantly higher, however, in mycorrhizal plant infected with Gl. geosporum (BEG11), as compared to the control. No significant differences were established in the calcium (Ca) or cobalt $(\mathrm{Co})$ concentrations of shoot between mycorrhizal and nonmycorrhizal plants. The magnesium $(\mathrm{Mg})$ concentration of shoots of plants infected with either Gl. mosseae strains or Gl. claroideum (BEG23) cultures were lower than in the shoots of control tomatoes. The effect of the two Gl. mosseae strains and Gl. claroideum (BEG23) culture on the Mg uptake of the host significantly differed from the response to inoculation with Gl. geosporum (BEG11) or Gl. fasciculatum (BEG53).

The inoculation with different Glomus sp. did not affect the shoots' copper $(\mathrm{Cu})$ content, while an intraspecific difference was established between Gl. mosseae (BEG12) and Gl. mosseae (H), which originates from a sandy soil in Hungary. Furthermore, the colonization of Glomus mosseae decreased the manganese (Mn) uptake of the host plant. The effect of Gl. geosporum (BEG11) on the shoots' Mn concentration was greater than in plants colonized with Gl. mosseae strains or Gl. claroideum (BEG23). As compared to the control or some Glomus sp. inoculated plants, the molybdenum (Mo) and zinc $(\mathrm{Zn})$ uptake of tomato was increased by the application of Gl. geosporum (BEG11). In shoots of Gl. mosseae (H) infected plants the $\mathrm{Zn}$ concentration was significantly lower than in any other sample. Both Gl. mosseae (BEG12 and H) inoculations caused a decrease in the nickel (Ni) uptake of tomato. In contrast to the present observations, an enhanced acquisition of $\mathrm{Co}, \mathrm{Cu}$, $\mathrm{Ni}, \mathrm{Zn}$ and other microelements was reported in mycorrhizal plants in comparison to non-mycorrhizal plants (CLARK \& ZETO, 2000; HARRIER \& WATSON, 2003). Similarly to our observations, the P and $\mathrm{N}$ uptake of tomato was increased by $\mathrm{Gl}$. mosseae inoculation as compared to the control (KARAGIANNIDIS et al., 2002). However, no difference in $\mathrm{K}, \mathrm{Ca}, \mathrm{Mg}$ and $\mathrm{B}$ uptake was observed between noninoculated and Gl. mosseae inoculated tomato. Lower concentrations of $\mathrm{Zn}, \mathrm{Mn}, \mathrm{Fe}$ and $\mathrm{Cu}$ micronutrients were detected in the presence of AM symbiosis.

Many studies stated that different AMF species improved the growth of different plant species and it proves the interspecific functional heterogeneity. The functional differences within AMF species, however, are less known. As a result of the differing colonization ability of AMF, the nutrient uptake activity is probable to vary in various fungal species (JAKOBSEN et al., 1992). ISOBE and TSUBOKI (1997) investigated the impact of Gigaspora margarita and Glomus sp. isolates on the growth of bean (Phaseolus vulgaris L.) in a phosphorus treated soil. The Glomus sp. inoculum yielded more biomass production of the host plant because of the higher infection frequency than the infection with Gigaspora margarita. MUNKVOLD et al. (2004) described the inter- and intraspecific functional diversity of some Glomus species, including Gl. mosseae isolates in relation to a phylogenetic analysis of large ribo- 
somal subunit (LSU) sequences. Great intraspecific variabilities were found in mycelium growth and impact on $\mathrm{P}$ uptake.

Host fungus compatibility was calculated from colonization parameters of various Glomus species in combination with the effect of AMF inoculation on plant growth, mycorrhizal dependency (MD) of host, macro- and microelement concentrations of tomato shoot. Using different AM fungi inocula the plant growth and nutrient uptake could be altered, as compared to the non-inoculated plants. The nutrient content of the mycorrhized host plants differed, depending on origin and AMF species, but was in accordance with the efficiency of the symbiosis. The development of an efficient (compatible) host-fungus association can promote the application of AMF inoculation as an environment-friendly biological tool for increasing plant production in sustainable agriculture (PLENCHETTE et al., 2005; QUILAMBO et al., 2005).

\section{Conclusions}

The inter- and intraspecific functional diversity of five Glomus cultures were studied in relation to plant response to AMF inoculation. The highest MD and element contents appeared in shoots of tomato treated with our Glomus mosseae strain, which may indicate a stronger affinity (compatibility) between the symbiotic partners. The results confirmed the hypothesis that indigenous AM fungi species or strains can be more efficient than other ones. These fungi are probably well adapted to the edaphic conditions of domestic soils. AM fungi application in horticulture is a possible simple and effective biotechnology for raising yields.

\section{Summary}

Arbuscular mycorrhizal (AM) fungi are obligatory biotrophic symbionts living in the roots of most terrestrial plants. AM fungi (AMF) have a positive effect on plant growth and plant nutrition, especially under stress conditions.

The aim of the present study was to observe the relationship between the mycorrhizal dependency and nutrient uptake of host plants and the rate of AMF colonization in a pot experiment. The degree of host growth responses to AMF colonization is expressed as mycorrhizal dependency (MD).

The pot trial was set up with a sterilized calcareous chernozem soil from Nagyhörcsök (Hungary) in a growth chamber under controlled climatic conditions. Tomato (Lycopersicon esculentum L.) plants were inoculated with Glomus claroideum (BEG23), Glomus fasciculatum (BEG53), Glomus geosporum (BEG11), Glomus mosseae (BEG12) strains and a Glomus mosseae AMF culture produced by authors. The dry biomass production, the micro- and macronutrient concentrations of the shoots and the parameters of the mycorrhizal infection were determined.

Each AM fungi species or isolate caused different and distinct changes in host plant growth and nutrient uptake. The biomass production of tomato increased sig- 
nificantly in the presence of AM symbiosis. The mean values of MD, calculated from shoot dry matter, varied between 36\% and 55\%. Mycorrhizal inoculation improved the $\mathrm{P}, \mathrm{N}$ and $\mathrm{K}$ uptake of tomato. The highest values for root colonization, frequency of infection or arbuscular richness were found in the root of tomato inoculated with the two Glomus mosseae strains. The highest MD and nutrient contents appeared in the shoot of tomato treated with our Glomus mosseae strain, which may indicate a stronger affinity (compatibility) between the symbiotic partners. The results confirmed that the selected AMF strains are applicable in sustainable horticulture.

The present study was supported by the Hungarian National Scientific Research Fund (OTKA) under grant F042543.

Key words: Glomus species, functional diversity, mycorrhizal dependency, compatibility, sustainable agriculture

\section{References}

AL-KARAKI, G. H., 2000. Growth of mycorrhizal tomato and mineral acquisition under salt stress. Mycorrhiza. 10. 51-54.

Azcón-Aguilar, C. \& BAREA, J. M., 1992. Interactions between mycorrhizal fungi and other rhizosphere microorganisms. In: Mycorrhizal Functioning: An Integrative Plant-Fungal Process. (Ed.: Allen, M. I.) 163-198. Chapman-Hall. New York.

AzCON, R. \& BAREA J. M., 1992. The effect of vesicular-arbuscular mycorrhizae in decreasing $\mathrm{Ca}$ acquisition by alfalfa plant in calcareous soils. Biol. Fertil. Soils. 13. $155-159$.

Clark, R. B. \& Zeto, S. K., 2000. Mineral acquisition by arbuscular mycorrhizal plants. J. Plant Nutr. 23. 867-902.

COOPER, K. M. \& TINKER, P. B., 1978. Translocation and transfer of nutrients in vesicular-arbuscular mycorhizas. II. Uptake and translocation of phosphorus, zinc and sulphur. New Phytol. 81. 43-52.

GerdemanN, J. W., 1965. Vesicular-Arbuscular Mycorrhizae formed on maize and tuliptree by Endogone fasciculata. Mycologia. 57. 562-575.

HARRIER, L. A. \& WATSON, C. A., 2003. The role of arbuscular mycorrhizal fungi in sustainable cropping systems. Advances in Agronomy. 79. 185-225.

IsOBE, K. \& TsUBOKI, Y., 1997. Study on utilization of arbuscular mycorrhizal fungi in kidney bean cultivation. Effects of available phosphorus content on the infection of arbuscular mycorrhizal fungi and two species of arbuscular mycorrhizal fungi on the growth of kidney bean (Phaseolus vulgaris L.). J. Crop. Sci. 66. 374-380.

JaKoBSEn, I., ABвOTt, L. K. \& RoBson, A. D., 1992. External hyphae of vesiculararbuscular mycorrhizal fungi associated with Trifolium subterraneum L. I. Spread of hyphae and phosphorus inflow into roots. New Phytol. 120. 371-380. 
JANOS, D. P., 1988. Mycorrhiza applications in tropical forestry: are temperate-zone approaches appropriate? In: Trees and Mycorrhiza (Ed.: NG, F. S. P.) 133-188. Forest Research Institute Malaysia. Kuala Lumpur.

Karagiannidis, N., Bletos, F. \& Stavropoulos, N., 2002. Effect of Verticillium wilt (Verticillium dahliae Kleb.) and mycorrhiza (Glomus mosseae) on root colonization, growth and nutrient uptake in tomato and eggplant seedlings. Scient. Hort. 94. 145-156.

Kubota, M., McGonigle, T. P. \& Hyakumachi, M., 2005. Co-occurrence of Arumand Paris-type morphologies of arbuscular mycorrhizae in cucumber and tomato. Mycorrhiza. 15. 73-77.

LANDWEHR, M. et al., 2002. The arbuscular mycorrhizal fungus Glomus geosporum in European saline, sodic and gypsum soils. Mycorrhiza. 12. 199-211.

MARSCHNER, H., 1997. The soil-root interface (rhizosphere) in relation to mineral nutrition. In: Mineral Nutrition of Higher Plants. (Ed.: MARSCHNER, H.) 537-594. Academic Press. London

MARSCHNER, H. \& Dell, B., 1994. Nutrient uptake in mycorrhizal symbiosis. Plant Soil. 159. 89-102.

MunKVOLD, L. et al., 2004. High functional diversity within species of arbuscular mycorrhizal fungi. New Phytol. 164. 357-364.

Nicolson, T. H. \& GerdemanN, J. W., 1968. Mycorrhizal Endogone species. Mycologia. 60. (2) 313-325.

PARÁDI, I., BRATEK, Z. \& LÁNG, F., 2003. Influence of arbuscular mycorrhiza and phosphorus supply on polyamine content, growth and photosynthesis of Plantago lanceolata. Biol. Plant. 46. 563-569.

PHILliPS, J. M. \& HAYMAN, D. S., 1970. Improved procedures for clearing roots and staining parasitic and VAM fungi for rapid assessment of infection. Trans. Brit. Mycol. Soc. 55. 158-161.

Plenchette, C., Fortin, J. \& Furlan, B.,1983. Growth response of several plant species to mycorrhizae in a soil of moderate P-fertility. I. Mycorrhizal dependency under field conditions. Plant Soil. 70. 199-209.

PlenchetTe, C. et al., 2005. Managing arbuscular mycorrhizal fungi in cropping systems. Can. J. Plant Sci. 85. 31-40.

Quilambo, O. A. et al., 2005. Arbuscular mycorrhizal inoculation of peanut in lowfertile tropical soil. I. Host-fungus compatibility. J. Plant Nutr. 28. 1633-1644.

RAJU, P. S. et al., 1987. Vesicular-arbuscular mycorrhizal infection effects on sorghum growth, phosphorus efficiency, and mineral element uptake. J. Plant Nutr. 10. 1331-1339.

REGVAR, M. et al., 2003. Effect of AMF inoculum from field isolates on the yield of green pepper, parseley, carrot, and tomato. Folia Geobotanica. 38. 223-234.

SCHENCK, N. C. \& SMith, G. S., 1982. Additional new and unreported species of mycorrhizal fungi (Endogonaceae) from Florida. Mycologia. 74. 77-92.

Schroeder, M. S. \& JANOS, D. P., 2004. Phosphorus and intraspecific density alter plant responses to arbuscular mycorrhizas. Plant Soil. 264. 335-348.

SIEVERDING, E., 1991. The mycorrhizal status of plant species. In: Vesicular-Arbuscular Mycorrhiza Managament in Tropical Agrosystems. (Ed. SIEVERDING, E.) 52-56. Deutsche Gesselschaft für Technische Zusammenarbeit. Eschborn 
SiMON, L. \& BIRÓ, B., 2005. Role of amendments, red fescue and Zn-tolerant mycorrhizal fungi in the remediation of a metal contaminated mine spoil from Gyöngyösoroszi. (In Hungarian) Agrokémai és Talajtan. 54. 163-176.

SzILI-KovÁCS, T., 2004. Substrate inducated respiration in soil. (In Hungarian) Agrokémia és Talajtan. 53. 195-214.

TAKÁCS, T. \& VÖRÖS, I., 2003. Role of the arbuscular mycorrhizal fungi in the water and nutrient supply of their host plant. (In Hungarian) Növénytermelés. 52. 583593.

TAKÁCS, T., RADIMSZKY, L \& NÉMETH, T., 2005. The arbuscular mycorrhizal status of poplar clones selected for phytoremediation of soils contaminated with heavy metals. Z. Naturforsch. 60. 357-361.

TAWARAYA, K., 2003. Arbuscular mycorrhizal dependency of different plant species and cultivars. Soil Sci. Plant Nutr. 49. 655-668.

Trouvelot, A., Kough, J. L. \& Gianinazzi-Pearson, V., 1986. Mesure du taux de mycorrhization VA d'un systeme radiculaire. In: Physiological and Genetical Aspects of Mycorrhizae. 1er Symposium Europeen sur les Mycorrhizes. (Eds.: GianinAZZI-PEARSON, V. \& GianinaZZI, S.) 217-221. INRA. Paris

WALKER, C., 1982. Species in the Endogonaceae: A new species (Glomus occultum) and a new combination (Glomus geosporum). Mycotaxon. 15. 49-61. 